\title{
Common Approaches to Patenting New E-commerce Business Models (a Case Study)
}

\author{
Max Gottlieb and Boris Stavrovski \\ City University of New York, NY, USA
}

MaxGot@aol.com, Stiminc@aol.com

\begin{abstract}
Three very typical examples of recently patented new E-commerce business models (commercial real estate transaction system, inventory database management system and Internet marketing resource allocating system) are analyzed. Common approaches to patenting new E-commerce business models are proposed and potential usefulness of patents as informing, marketing and protective instruments is discussed.
\end{abstract}

Key words: E-commerce, informing science, marketing, patents.

\section{Introduction}

The development of electronic commerce utilizing numerous publicly available databases has greatly expanded the number of products and services that can be accessed effectively via the Internet. These products and services range from simple objects that are easily described by several main features (i.e., books, airplane tickets, cars, etc.) to more complicated, less standardized products (i.e., real estate, medical, legal, and financial services). The tremendous growth of ecommerce has made it important to reconsider how best to protect emerging technologies and new methods of doing business. Organizations concerned with e-commerce typically use computer software to facilitate their on-line commercial transactions and often employ new methods of doing business to provide their services. Accordingly, the protection of business methods and computer software is of increasing significance to the e-commerce industry (Shu-Tai \& Van Barr, 2000). A patent grants a property right to an inventor for 20 years, prohibiting others from using the invention in the U.S (McGeever, 2000). As companies venture into the un-chartered territory of e-commerce, many of them seek to patent their work (Alexander, 2000). Similar processes are taking place in Europe (Lang, 2000).

US patent law declares that the question is not whether there is a mathematical algorithm involved or whether the claimed subject matter does "business", but rather whether the algorithmcontaining invention as a whole produces a useful, concrete and tangible result, which means that specific, practical applications of algorithms are patentable (Durant \& Chuang, 2000). Examples of such e-commerce patents are well known to all interested in the field (Alexander, 2000):

AMAZON.COM's patented one-click system enables repeat online customers to place orders

Material published as part of this journal, either on-line or in print, is copyrighted by Informing Science. Permission to make digital or paper copy of part or all of these works for personal or classroom use is granted without fee provided that the copies are not made or distributed for profit or commercial advantage AND that copies 1) bear this notice in full and 2) give the full citation on the first page. It is permissible to abstract these works so long as credit is given. To copy in all other cases or to republish or to post on a server or to redistribute to lists requires specific permission from the publisher at Publisher@InformingScience.org without re-entering credit-card or address information. Part of the patent covers the way Amazon stores billing and shipping data. In 2000, Amazon obtained a preliminary court injunction against Barnesandnoble.com that prevents the Amazon competitor from using the one-click system. 
PRICELINE.COM patented a method by which a customer could propose a price for a product or service, and the order would be filled if a seller was willing to accept that price. Priceline.com sued Microsoft Corp. and its Expedia Inc. travel service for allegedly violating Priceline's method of letting consumers propose their own prices for flights and hotel rooms. Simultaneously, Priceline.com used its patented business model as an aggressive marketing tool, trying to attract as many potential new customers as it became possible. Thus, one another and very important function of the patent as an informing and marketing tool have been introduced.

Open Market Inc. (Duvall, 1998) has received three patents from the U.S. Patent and Trademark Office covering fundamental technologies for doing business over the Internet:

- Digital Payments (Patent No. 5,724,424). Covers secure, real-time payment using credit and debit cards over the Internet. Open Market claims it is one of the earliest and broadest Internet payment patents granted, with a filing date of Dec. 16, 1993.

- Internet Server Access Control and Monitoring Systems (Patent No. 5,708,780). Covers the ability to analyze how users browse through content on a Web site. Session identifiers allow businesses to market more effectively to buyers based on their viewing patterns.

- Network Sales System (Patent No. 5,715,314). Covers the use of electronic shopping carts, which merchants provide to their customers as a way to accumulate items before purchasing.

Searchable database of patents on the Internet (and in particular, one created by United States Patent and Trademark Office - $\mathrm{http}: / /$ www.uspto.gov/patft/index.html) shows that some established in E-commerce area companies are still having (December 2004) very small number of patents as assignees - 22 for Yahoo, 14 for Priceline.com, 8 for E-bay, 7 for Google, 4 for AOL, 3 for Amazon etc. These numbers being not very impressive by itself are becoming even more disappointing in comparison with some computer and software giants: 3606 for Microsoft, 1861 for Apple, 1141 for Dell, 540 for IBM etc.

\section{New E-business Models Chosen for the Case Study}

\section{Description of the Commercial Real Estate Transaction System}

A new transaction system for implementing complex business transactions via the Internet has been patented (Stavrovski, 2002). The system includes components responsible for search, market analysis, negotiation, and legal closing, and its implementation is able to:

- quantitatively evaluate preferences of potential customers (tenants and landlords), and define permissible search areas and allowable ranges for bargaining

- search all publicly available databases and generate a statistical model of the current market situation and future tendencies as they relate to the customer's preferences

- organize interactive multi-party negotiations pertaining to the information received, and formulate suggestions that will establish the basis for a compromise.

The system performs a recurrent sequence of the following seven steps:

\section{Creating the tenant's profile}

After establishing the initial interactive contact with the potential buyers/ tenants through the communication means over the Internet, the system is analyzing their actual preferences in the space of the objects' parameters and in the space of contract terms parameters. The utility evaluation unit of the system is programmed to generate approximations of multi-attitude utility and 
flexibility functions for the potential buyers/ tenants. The admissible domain for the consecutive search of commercial real estate objects may be defined on that basis.

\section{Searching for admissible objects}

The system contacts through the communication means over the Internet all publicly available databases, which may contain information about commercial real estate objects, and organizes the search of admissible objects inside of the search domain defined at the previous step. The search unit of the system is programmed to search said databases and to generate the first list of admissible objects in accordance with the buyer's/tenant's preferences. In the case when the first list contains no objects (no admissible objects were found) the system returns recurrently to the first step of the whole procedure with the suggestion to change buyer's/tenant's preferences (to enlarge the search domain). If the buyer/tenant disagrees with the suggested changes the system cancels all procedure.

\section{Implementing market analysis}

On the basis of information delivered from the publicly available databases the system creates the statistical models of the market situation and tendencies at the proximity of the first list of objects. The market analysis unit of the system is programmed to analyze the models of the marginal market evaluations and the models of the prevailing (asking and selling) market contract terms. The system contacts the potential buyer/tenant again with the purpose to inform about the marginal prices of the objects' parameters from the first list and about marginal prices of the contract parameters for the same objects, and it returns recurrently to the first step of the whole procedure, if the buyer/tenant decides to change preferences. If the buyer decides not to change preferences the system confirms the already existing first list of objects.

\section{Creating a list of negotiable objects}

The system eliminates objects from the first list, which are situated in contradiction with the statistical models of the market situation and tendencies (fair price hypothesis), thus generating the second shorter list of negotiable objects. In the case when the second list contains no objects, the system returns recurrently to the first step of the whole procedure with the suggestion to change buyer's/tenant's preferences (to enlarge the search domain). If the buyer/tenant disagrees with the suggested changes the system cancels all procedure.

\section{Creating the landlord's profile}

After establishing the initial interactive contact with the potential sellers/landlords of the objects from the second list through the communication means over the Internet, the system evaluates their actual preferences in the space of negotiable contract parameters. The utility evaluation unit of the system is programmed to generate approximations of multi-attitude utility and flexibility functions for the potential sellers/landlords. The admissible domain for the negotiations is defined on that basis.

\section{Hosting the negotiations and correcting previous steps if necessary.}

The system organizes the processes of simultaneous interactive negotiations at the admissible negotiation domains between the buyer/tenant and each of the sellers/landlords and formulates suggestions that may constitute the basis of compromises for the each pair buyer/seller.

The system generates the third list of the objects, for which the compromises between the buyer and any one of the sellers are agreed upon by both of them. After that the system designates the final object from the said third list, for which the result of the negotiation is best for the buyer/tenant. The system obtains the buyer's and seller's approvals for finalizing the transaction. The negotiation unit of the system is programmed to fulfill these parts of the step 6 . 
In the case, when the third list contains no objects, the system returns recurrently to the first step of the whole procedure with the suggestion to change buyer's/tenant's preferences (to enlarge the search domain). If the buyer/tenant disagrees with the suggested changes the system cancels all procedure.

7. Organizing the due diligences processes.

The system generates all necessary legal documents and organizes the processes of due diligence and legal closing, thus successfully finishing the procedure. The due diligence unit of the system is programmed to fulfill this part of the step 7.

If the due diligence process finishes unsuccessfully, the system returns recurrently to the next object from the third list. In the case when said third list contains no more objects, the system returns recurrently to the first step of the whole procedure with the suggestion to change buyer's/tenant's preferences (to enlarge the search domain). If the buyer/tenant disagrees with the suggested changes the system cancels all procedure.

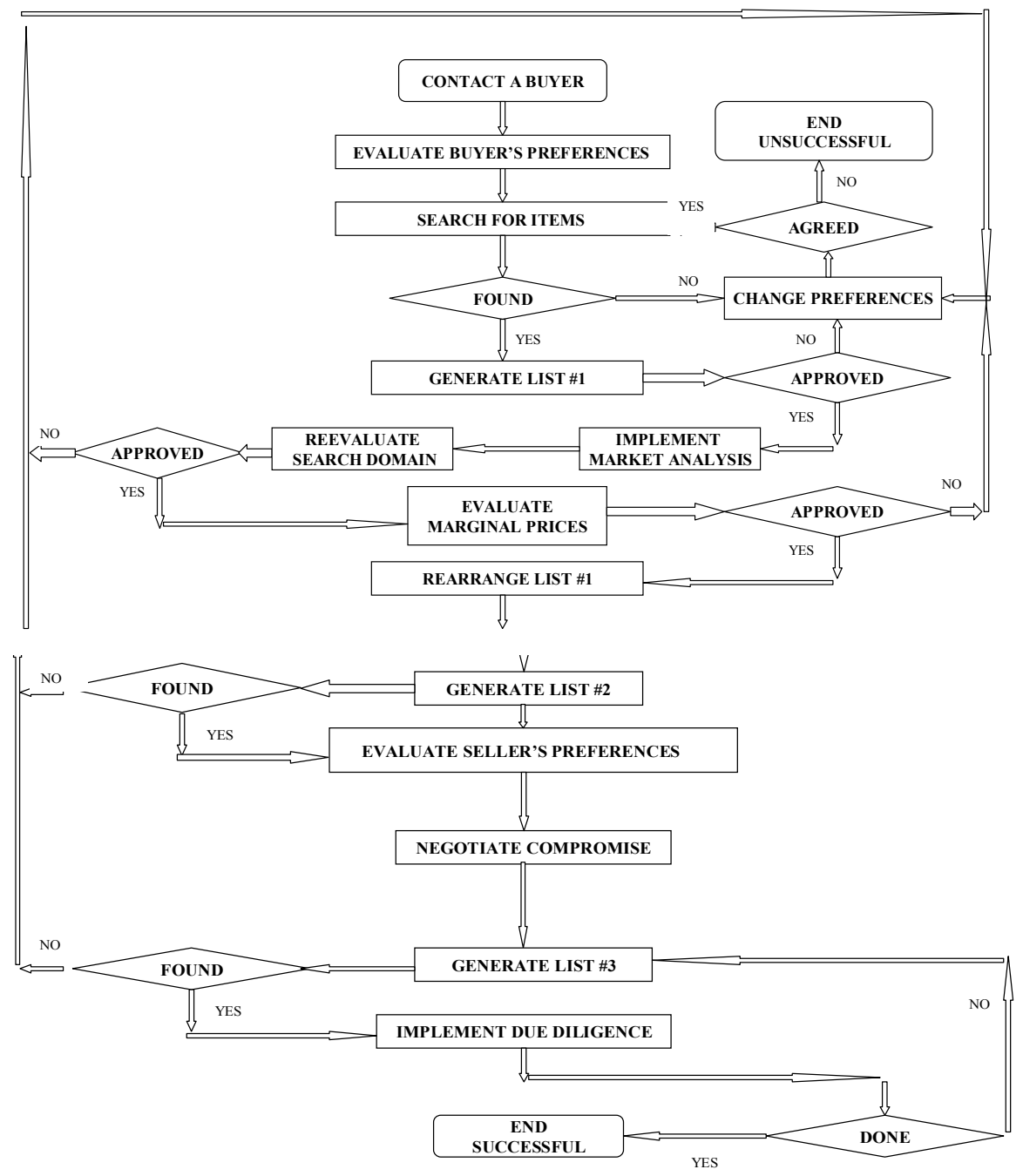

Figure 1. A flow chart for commercial real estate method operations 
As an example of a practical implementation of these methodological concepts, the system described in detail in (Stavrovski, 2002) for implementation of a commercial real estate deal via the Internet has been designed.

Figure 1 illustrates how this consequence of seven steps may be rearranged and interpreted graphically in a form of a flow chart for method operations (a necessary formal part for any patent specification).

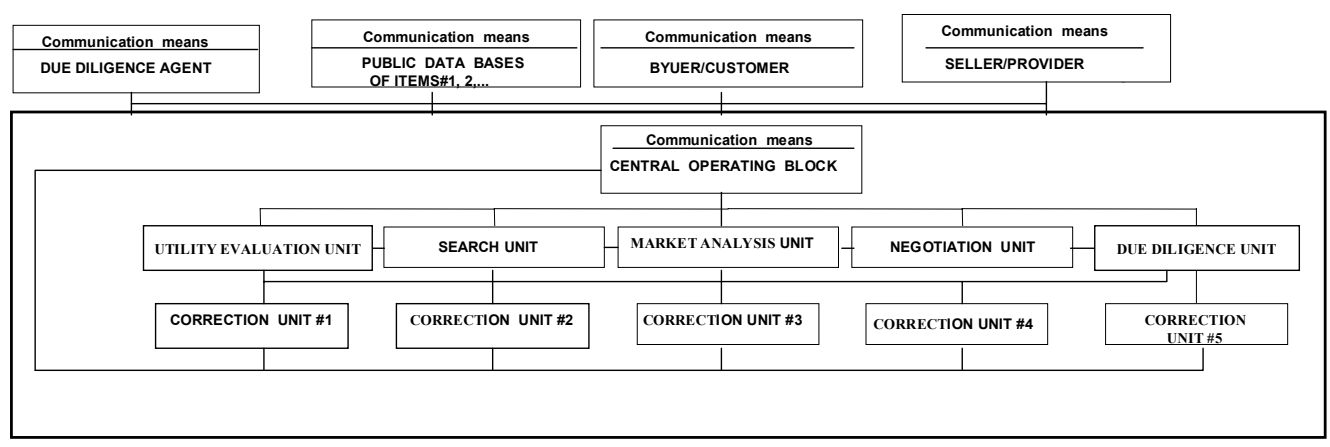

Figure 2. A block diagram of the commercial real estate transaction system.

Figure 2 illustrates a greatly simplified block diagram of the primary elements of the computerbased system, which was employed for carrying out the commercial real estate transaction via the Internet. The computer-based system includes a potential buyer's/tenant's computer terminal with its communication means (i.e., modem and phone line, with possibilities to be connected with other parts of the system via the Internet), a plurality of publicly available databases hosted via the Internet with its communication means, a plurality of potential sellers'/landlords' computer terminals with their communication means, a plurality of due diligence agents' computer terminals with their communication means and finally, a central operating block with its communication means. Activities of a central operating block are designated for combining the system to function as a whole creation rather than as a simple collection of independent elements.

Having these two main elements of the specification prepared (flow chart of the operations for the method and block diagram of the primary elements for the system), it becomes evident how to formulate main independent claims of the patent (Stavrovski, 2002).

\section{Description of the Dynamic Inventory Database Management (DIDM) System}

The DIDM system (Frid \&Stavrovski, 2003) performs a recurrent sequence of the following four steps:

Step 1: Creating the Database Structure

Using the information from the new database customer, the DIDM System creates the initial list of locations and their attributes, the initial list of items and their attributes, and the evaluation record of customer preferences about ageing of the database inventories. The initial list of items and their attributes includes dynamic and static, controllable and uncontrollable attributes.

Step 2: Creating Initial (First Shot) Database 
First, the DIDM System registers particular values for the attributes of the locations and creates the files of attributes for each of the locations. Second, the DIDM System generates particular initial values for the controllable dynamic and static attributes of items for each of the locations. Third, the System registers the initial values for the controllable dynamic and static attributes of items with initial values for the uncontrollable dynamic and static attributes for each of the locations. Fourth, the System transmits the files of the attributes of the locations, the initial values for the controllable dynamic and static attributes of items with the initial values for the uncontrollable dynamic and static attributes of items for each of the locations, into the central data warehouse via the Internet. Fifth, the System creates the initial section of inventory database at the central data warehouse and sends the initial report to the user via the Internet.

Step 3: Implementing Regular System Updates

The DIDM System performs regular updates based on the actual customer preferences about different ageing characteristics of database content. The System determines the updating periodicity $\Delta \mathrm{t}_{\mathrm{u}}$, which requires the system to perform Step 1 and Step 2 on a regular basis. Specifically, the System updates the changes of files of the attributes of locations, the initial values for the controllable dynamic attributes of items, and updates the changes of the initial values for the uncontrollable dynamic attributes of items for each of the locations. Then, the System sends a report to users via the Internet and supplies them with necessary software tools to implement an entire range of operations via the Internet.

If a stable connection via the Internet is available, examples of possible operations include querying the current inventory database, requesting irregular updates of the current inventory database, changing the current lists of locations and/or the attributes of locations, if changes could be done by the customer on one's own, or filing via the Internet the request for these changes to be implemented by the central data warehouse. A database user can also change the current lists of items and/or the dynamic and/or static controllable and/or uncontrollable attributes of items for each or some of the locations, if changes could be done by the customer on one's own, and file via the Internet the request for these changes to be implemented by the central data warehouse.

When an incoming query does not require an irregular update or a stable connection via the Internet is not available, the System queries the current section of inventory database and sends (using conventional connection means if necessary - like phone, fax, etc) a report to the customer with the information necessary to satisfy the customer's request.

Step 4: Implementing Irregular System Updates

When an incoming query requires an irregular update, the DIDM System recurrently returns to Step 1 and Step 2 and implements the required changes in attributes of items for some or for all of the locations, and in the description of customer preferences. After completing these updates, the DIDM System sends a confirmation via the Internet to the inventory user, stating the changes that were made according to the user's requests.

Figure 3 illustrates how this consequence of four steps may be rearranged and interpreted graphically in a form of a flow chart for method operations.

Figure 4 illustrates a greatly simplified block diagram of the primary elements of the computerbased DIDM system.

Having these two main elements of the specification prepared (flow chart of the operations for the method and block diagram of the primary elements for the system), it becomes evident how to formulate two main independent claims of the patent (Frid \&Stavrovski, 2003). 


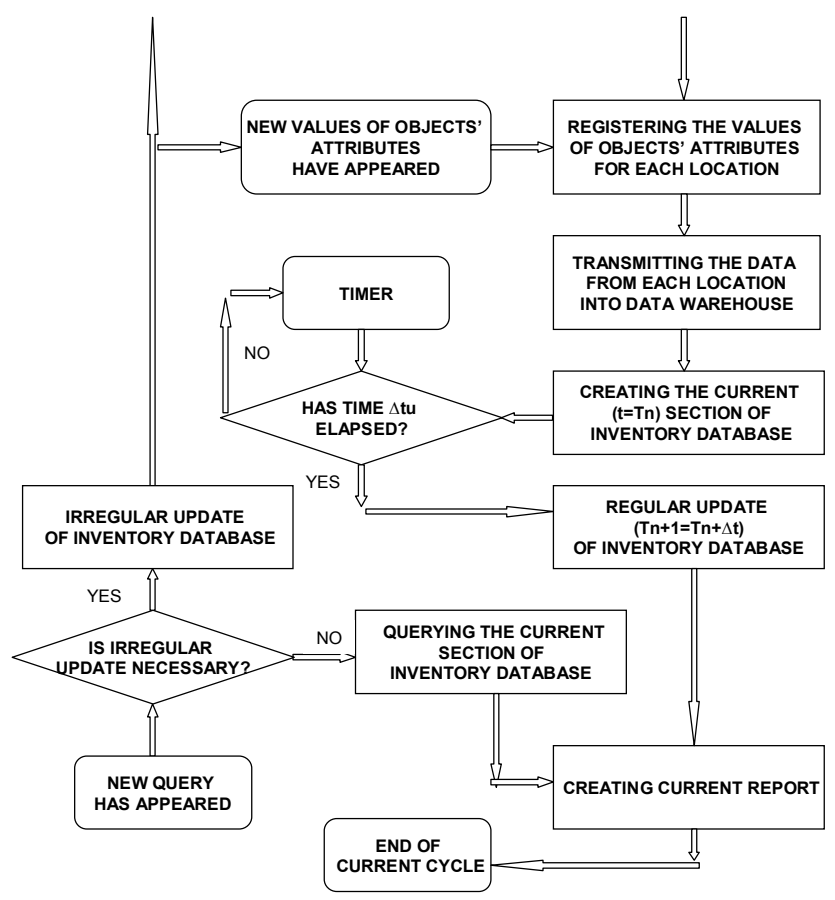

Figure 3. A flow chart for DIDM method operations
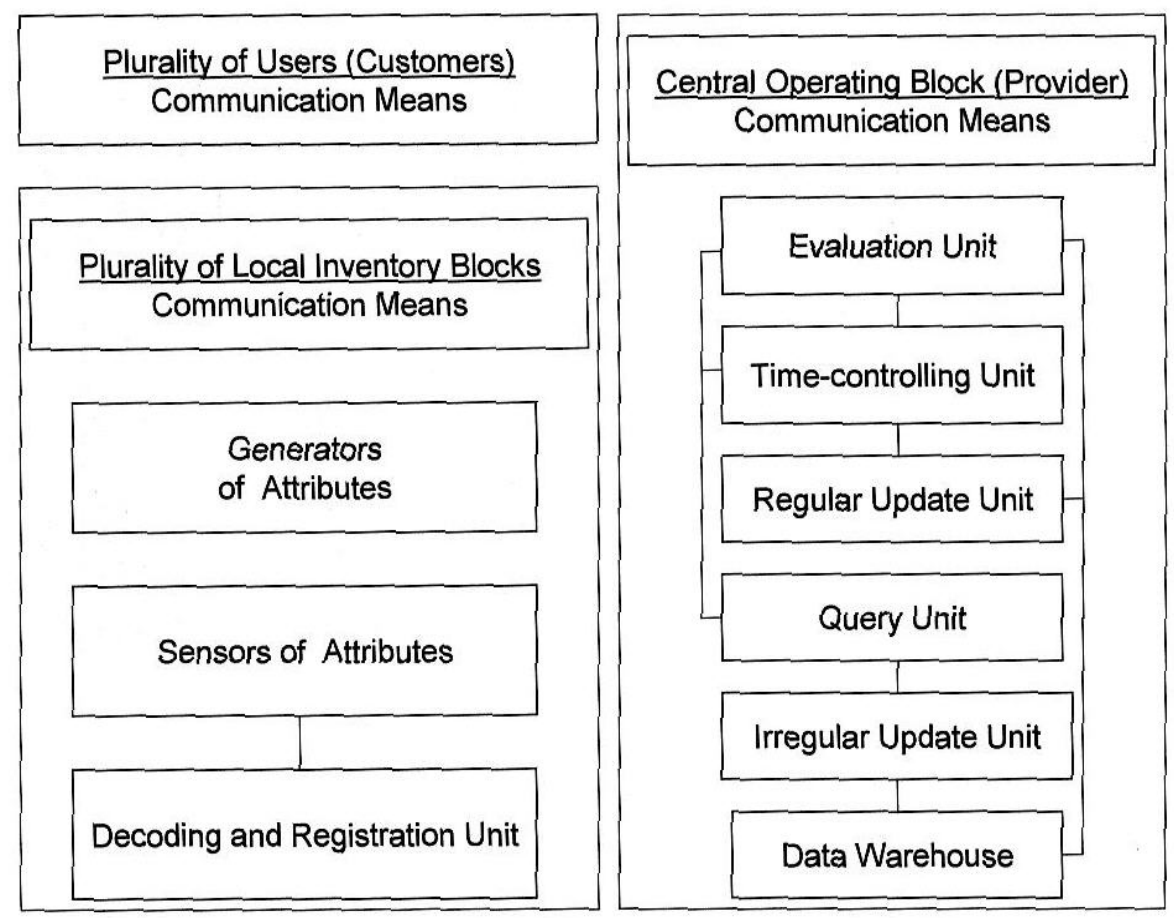

Figure 4. A block diagram of the DIDM management system 


\section{Description of the Internet Marketing Resource Allocating System}

A method and decision support system for optimal allocation of expendable resources in any type of repetitive business transaction with resource-dependant effectiveness and use of a-posteriori information (Stavrovski, 2004) i.e., internet marketing (IM) transaction, in which the computerized system:

- creates the list of IM providers to be considered, contacts them over the Internet, and collects from them the a-priori data about EMO available and resource-dependant effectiveness of these EMO;

- chooses the optimal resource allocation DMR for EMO to be implemented and calculates optimal resource-dependant effectiveness parameters for the first EMO;

- implements the first EMO, evaluates its results through direct or indirect (using IM provider as intermediary) Internet contact with marketing addressees who responded for the first EMO thus collecting a-posteriori data on EMO effectiveness;

- checks the current status of resources available and proceeds according to recommendations of optimal DR chosen previously to the next EMO if resources are available, or ends the current IM operation otherwise;

- calculates optimal resource-dependant effectiveness parameters for the next EMO, implements the next EMO, and evaluates its results through direct or indirect (using IM provider as intermediary) Internet contact with marketing addressees who responded for that EMO thus collecting a-posteriori data on EMO effectiveness;

- recurrently returns to two previous steps of the procedure.

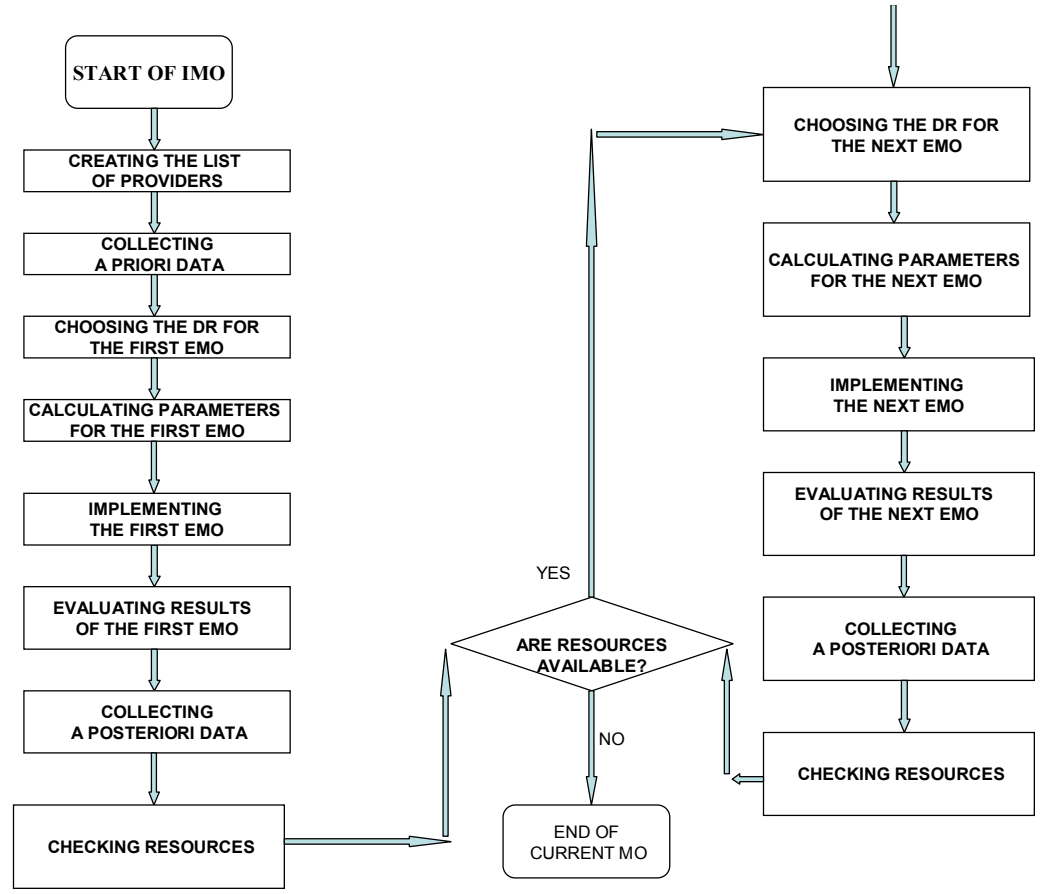

Figure 5. A flow chart for IM resource allocation method operations 
As an example of a practical implementation of these methodological concepts, the system described in detail in (Stavrovski, 2002) for implementation of a commercial real estate deal via the Internet has been designed.

Figure 5 illustrates how this consequence of six steps may be rearranged and interpreted graphically in a form of a flow chart for method operations.

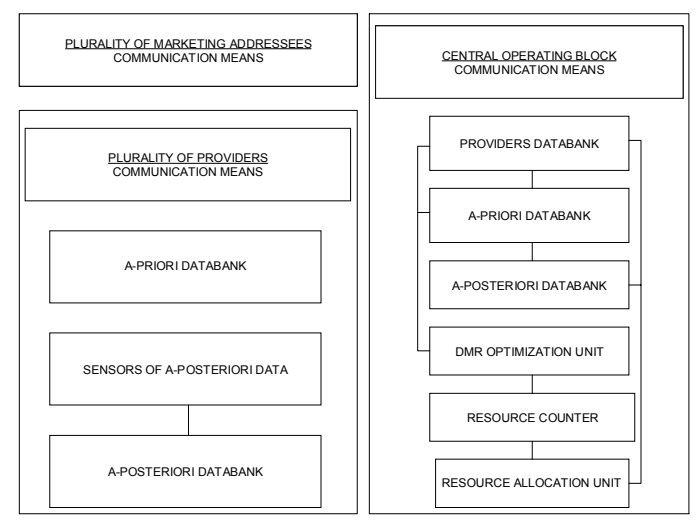

\section{Figure 6. A block diagram of the Internet marketing re- source allocation system}

Figure 6 illustrates a greatly simplified block diagram of the primary elements of the computerbased system, which was employed for carrying out the Internet marketing operation.

Having these two main elements of the specification prepared (flow chart of the operations for the method and block diagram of the primary elements for the system), it becomes evident how to formulate two main independent claims of the patent (Stavrovski, 2004).

\section{Conclusion}

Formal analysis of three typical cases of patent specifications content for recently patented new E-commerce business models (commercial real estate transaction system, inventory database management system and Internet marketing resource allocating system) has elicited some common features:

- an E-commerce business model first should be described as a consequence of steps (operations) with details of content and resource requirements clarified for each step;

- this consequence of steps should be rearranged and interpreted graphically in a form of a flow chart for method operations;

- primary elements of a computer-based system responsible for implementation of each method operation (or parts of thereof) should be proposed as parts of a block diagram;

- proper relationships (connections) between different elements of a block diagram should be established in accordance with a flow chart created earlier;

- two main independent claims (for a method and for a system) might be formulated as a final step of specification preparation.

Individual differences of various E-commerce business models are reflected not only in a specificity of main method operations or system blocks but also in additional dependent claims that are typically present in any particular patent as well. 
Searchable databases of patents on the Internet (either created by United States Patent and Trademark Office or by IBM) constitute a valuable but still not enough appreciated instrument of marketing and informing third parties in E-commerce business problematic.

\section{References}

Alexander, S. (2000). Patents in E-Commerce. Computerworld, 34 (17), 58-59.

Durant, S. C. \& Chuang, T. C. (2000). E-Commerce patents and shifting balances in patent law. IEEE Communications Magazine, 38 (7), 106-111.

Duvall, M. (1998). Open Market claims key e-commerce patents. Interactive Week, 5 (9), 14-17.

Frid, Y. \& Stavrovski, B. (2003). Method and system for computerized creating, maintaining, updating, and querying inventory database over the internet for the locations and the items with time-dependent and time-independent attributes. Patent USA pending \#10/606416, 06/27/2003

Lang, J. (2000). Europe grants e-commerce patents too. Managing Intellectual Property, 97, 18-19.

McGeever, C. (2000). Patent office plans reforms aimed partly at e-commerce. Computerworld, 34 (14), $40-42$.

Shu-Tai, C. \& Van Barr, C. (2000). Protecting e-commerce assets in Canada. Managing Intellectual Property, 102, 11-13.

Stavrovski, B. (2004). Method and decision support system for optimal allocation of expendable resources in internet marketing with resource-dependant effectiveness and use of a-posteriori information. Patent USA pending \#10/942111, 09/15/2004

Stavrovski, B. (2002) Method and system for implementing a business transaction over the Internet with use and consecutive transformation of information from publicly available databases, actual preferences of potential customers and statistical models of the market situation. Patent USA pending \#10/172064 06/17/02. Published 12.18.2003.
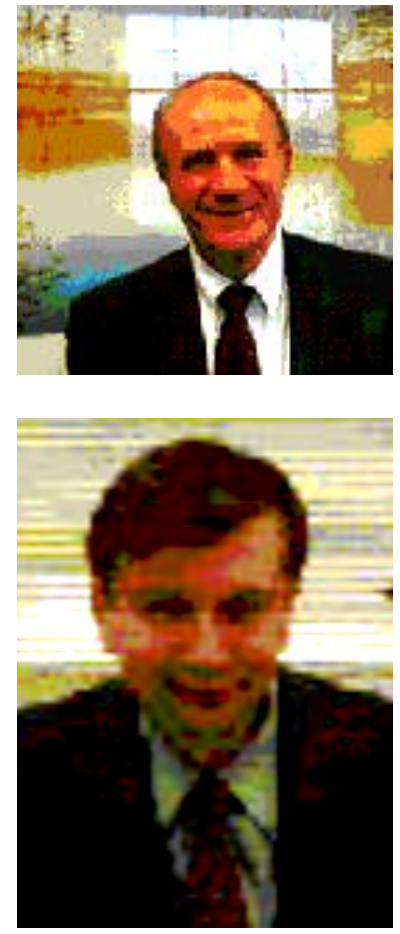

\section{Biographies}

Max Gottlieb is a Professor of Information Systems and Accounting at the College of Staten Island, The City University of New York. He is the coordinator of the Information Systems program. Prior to joining the academic world, Dr. Gottlieb worked as a project manager and a consultant developing computer systems for large institutions. He has published numerous articles and two books and has presented several papers at conferences. A Certified Public Accountant, Dr. Gottlieb has a doctorate degree from Gdansk University (Poland) and an MBA and B.S. from New York University.

Boris Stavrovski is an Assistant Professor of Information Systems in the Business Department at the College of Staten Island, The City University of New York. Dr. Stavrovski received his Doctor of Sciences degree in operations research, Ph.D. degree in information technologies, his MBA degree in avionics industry, and his BS in wide band communication devices from The Moscow Aviation Technical University in Russia. His research interests include enterprise strategy and policy analyses for e-commerce and Web design. Dr. Stavrovski has published in refereed journals and presented his research at international conferences. 